\title{
Sub-Anesthetic Ketamine Modulates Intrinsic BOLD Connectivity Within the Hippocampal-Prefrontal Circuit in the Rat
}

\author{
Natalia Gass*,', Adam James Schwarz ${ }^{2,3}$, Alexander Sartorius ${ }^{1,4}$, Esther Schenker ${ }^{5}$, Celine Risterucci ${ }^{6}$, \\ Michael Spedding ${ }^{5}$, Lei Zheng ${ }^{1,7}$, Andreas Meyer-Lindenberg ${ }^{4}$ and Wolfgang Weber-Fahr' \\ 'Department of Neuroimaging, Central Institute of Mental Health, Medical Faculty Mannheim, University of Heidelberg, Mannheim, Germany; \\ ${ }^{2}$ Translational Medicine, Eli Lilly, Indianapolis, IN, USA; ${ }^{3}$ Department of Psychological and Brain Sciences, Indiana University, Bloomington, IN, \\ USA; ${ }^{4}$ Department of Psychiatry and Psychotherapy, Central Institute of Mental Health, Medical Faculty Mannheim, University of Heidelberg, \\ Mannheim, Germany; ${ }^{5}$ Neuroscience Drug Discovery Unit, Institut de Recherches Servier, Croissy s/Seine, France; ${ }^{6}$ CNS Biomarker, \\ Pharmaceuticals Division, F Hoffmann-La Roche, Basel, Switzerland; ' Experimental Radiation Oncology, University Medical Center Mannheim, \\ University of Heidelberg, Mannheim, Germany
}

\begin{abstract}
Dysfunctional connectivity within the hippocampal-prefrontal circuit (HC-PFC) is associated with schizophrenia, major depression, and neurodegenerative disorders, and both the hippocampus and prefrontal cortex have dense populations of $N$-methyl-D-aspartate (NMDA) receptors. Ketamine, a potent NMDA receptor antagonist, is of substantial current interest as a mechanistic model of glutamatergic dysfunction in animal and human studies, a psychotomimetic agent and a rapidly acting antidepressant. In this study, we sought to understand the modulatory effect of acute ketamine administration on functional connectivity in the HC-PFC system of the rat brain using resting-state $\mathrm{AMRI}$. Sprague-Dawley rats in four parallel groups ( $N=9$ per group) received either saline or one of three behaviorally relevant, sub-anesthetic doses of S-ketamine (5, 10 , and $25 \mathrm{mg} / \mathrm{kg}$, s.c.), and connectivity changes I5- and 30-min postinjection were studied. The strongest effects were dose- and exposure-dependent increases in functional connectivity within the prefrontal cortex and in anterior-posterior connections between the posterior hippocampus and retrosplenial cortex, and prefrontal regions. The increased prefrontal connectivity is consistent with ketamine-induced increases in HC-PFC electroencephalographic gamma band power, possibly reflecting a psychotomimetic aspect of ketamine's effect, and is contrary to the data from chronic schizophrenic patients suggesting that ketamine effect does not necessarily parallel the disease pattern but might rather reflect a hyperglutamatergic state. These findings may help to clarify the brain systems underlying different dose-dependent behavioral profiles of ketamine in the rat. Neuropsychopharmacology (2014) 39, 895-906; doi:I0.1038/npp.2013.290; published online 20 November 20I3
\end{abstract}

Keywords: ketamine; functional connectivity; hippocampal-prefrontal; preclinical

\section{INTRODUCTION}

The hippocampal-prefrontal circuit (HC-PFC), one of the key pathways mediating cognition and memory, is affected in several psychiatric and neurodegenerative disorders, with dysfunctional connectivity within this circuit being increasingly detected in schizophrenia and major depression, and Alzheimer's disease (Goveas et al, 2011; Hasler and Northoff, 2011; Zhou et al, 2008). In patients with paranoid schizophrenia, functional connectivity as measured by lowfrequency blood oxygenation level-dependent (BOLD) oscillations has been found to be in the absence of any

\footnotetext{
*Correspondence: Dr N Gass, Department of Neuroimaging, Central Institute of Mental Health, Medical Faculty Mannheim, University of Heidelberg, J5, Mannheim 68I59, Germany, Tel: +49 0621 I7032966, E-mail: natalia.gass@zi-mannheim.de

Received 3 June 2013; revised 21 August 2013; accepted 18 September 2013; accepted article preview online 18 October 2013
}

task (Rotarska-Jagiela et al, 2010; Zhou et al, 2008). In contrast, persistent increases in HC-PFC connectivity has been observed during working memory tasks in schizophrenic patients, subjects at risk, and subjects with firstepisode psychosis (Crossley et al, 2009; Meyer-Lindenberg et al, 2005).

The hippocampus and prefrontal cortex have dense populations of $N$-methyl-D-aspartate (NMDA) receptors. Ketamine, a potent NMDA receptor antagonist, is of substantial current interest both as a psychotomimetic agent (Javitt et al, 2012) and a rapidly acting antidepressant, effective in treatment-resistant depressive patients (Zarate et al, 2006). Furthermore, ketamine (and other NMDA receptor antagonists) are widely studied in both healthy human volunteers and laboratory animals and represent a translatable pharmacological model of glutamatergic dysfunction in psychiatric disorders (Large, 2007). The neurobiological substrates of the effects of these compounds have begun to be investigated in both rodents and humans 
using neuroimaging techniques (Doyle et al, 2013; Gozzi et al, 2008). Recently, the effects of ketamine on restingstate BOLD connectivity have been demonstrated in humans (Driesen et al, 2013; Niesters et al, 2012; Scheidegger et al, 2012), but remain to be elucidated in preclinical species.

This study represents the first investigation of the effects of acute ketamine administration on BOLD functional connectivity in the rat. We assessed three doses $(5,10$, $25 \mathrm{mg} / \mathrm{kg}$ s.c.) covering a range that has been shown to elicit cognitive, behavioral, imaging, electrophysiological, and neurotransmitter signal changes in a number of studies (Kamiyama et al, 2011; Littlewood et al, 2006; Lorrain et al, 2003; Phillips et al, 2012). We focused on the HC-PFC network as a key hypothesized substrate of cognitive and emotional deficits in central nervous system disorders such as schizophrenia (Godsil et al, 2013) and following our recent characterization of the HC-PFC connectivity signature in the rat brain (Schwarz et al, 2013) that provides a foundation for investigating perturbations of this pathway by drug and/or endophenotype.

\section{MATERIALS AND METHODS}

Thirty-six Sprague-Dawley male rats (368-447 g; Janvier Laboratories, Le Genest-St-Isle, France) were used for fMRI experiments. All animals were housed under controlled conditions $\left(19-23{ }^{\circ} \mathrm{C}, 40-60 \%\right.$ humidity) on a $12: 12 \mathrm{~h}$ lightdark cycle (lights on at 0700 hours).

All procedures were conducted according to the regulations covering animal experimentation within the European Union (European Communities Council Directive 86/609/ EEC) and within the German Animal Welfare Act. Experiments were approved by the German animal welfare authorities (Regierungspräsidium Karlsruhe).

\section{MRI Acquisition}

Experiments were conducted at a 94/20 Bruker Biospec MRI scanner (9.4 T; Bruker BioSpec, Ettlingen, Germany) with Avance III hardware, BGA12S gradient system with the maximum strength of $705 \mathrm{mT} / \mathrm{m}$, and running Paravision 5.1 software. Transmission and reception were accomplished using a linear whole-body volume transmitter coil combined with an anatomically shaped four-channel receive-only coil array for the rat brain. Rats were anesthetized with $4 \%$ isoflurane (Baxter Deutschland $\mathrm{GmbH}$, Unterschleissheim, Germany) in a mixture of $\mathrm{N}_{2}$ (70\%) and $\mathrm{O}_{2}(30 \%)$. After positioning in the scanner (head first, prone), isoflurane at $\sim 2.5 \%$ was supplied for adjustments. Then, a bolus of $0.5 \mathrm{ml}$ medetomidine solution (Domitor, Janssen-Cilag, Neuss; $0.07 \mathrm{mg} / \mathrm{kg}$ s.c.) was injected; isoflurane was slowly discontinued within the next $10 \mathrm{~min}$, after which a continuous infusion of medetomidine solution was started at $0.14 \mathrm{mg} / \mathrm{kg} / \mathrm{h}$ rate. Breathing and cardiac rates were monitored using a respiration pad placed beneath the chest (Small Animal Instruments, NY) and a pulse oximeter attached to the hindpaw, respectively. Signals were recorded (10-ms resolution) using a signal breakout module (Small Animal Instruments) and a fourchannel recorder (Velleman NV, Gavere, Belgium) together with the scanner trigger pulses for each measured brain volume.

The resting-state fMRI (rs-fMRI) time series were acquired using an echo-planar imaging (EPI) sequence with the following parameters: repetition time/echo time (TR/TE) $1700 / 17.5 \mathrm{~ms}$, flip angle $60^{\circ}, 1$ segment, 29 coronal slices (ascending slice order), $96 \times 96$ imaging matrix, field of view $35 \times 35 \mathrm{~mm}^{2}$, slice thickness $0.5 \mathrm{~mm}$ with $0.2 \mathrm{~mm}$ inter-slice gap, 300 acquisitions over $8.5 \mathrm{~min}$. The in-plane voxel dimension was $0.365 \mathrm{~mm}$ and the slice stack covered the brain from the cerebellum to the posterior olfactory bulb.

\section{Experimental Design}

The experimental design comprised four parallel groups of $N=9$ rats each. In three of the groups, S-ketamine (Ketanest, Pfizer Pharma GmbH, Berlin, Germany) was injected s.c. at one of three doses $(5,10$, or $25 \mathrm{mg} / \mathrm{kg}$ ) dissolved in saline (total volume $1 \mathrm{ml} / \mathrm{kg}$ ). The fourth group received the same volume of vehicle (saline). As the first investigation into the effects of ketamine on functional connectivity in the rat, this was an exploratory study. As such, no formal power calculation was performed. As 7-10 animals per group is typical of rodent fMRI studies, the group size of $N=9$ per dose in our study was judged sufficient to detect the direction and effect size of the main effects of ketamine and to yield more specific hypotheses to be tested in subsequent confirmatory studies.

The MRI acquisition protocol for each animal comprised a FieldMap and three rs-fMRI time series. The first (baseline) rs-fMRI series was acquired approximately 20 min after the start of medetomidine continuous infusion. The ketamine/saline injection was then performed immediately after acquiring this first rs-fMRI data set, which is $28.5 \mathrm{~min}$ after the start of medetomidine continuous infusion and a respective discontinuation of isoflurane supply. The second EPI sequence started at $15 \mathrm{~min}$ after the ketamine/vehicle injection and the third-at 30-min postinjection. We selected these two time points to profile the expected peak period of post-injection pharmacodynamic effects based on gamma power changes from electrophysiology measurements after s.c. ketamine injection (Phillips et $a l, 2012$ ) and the relatively rapid pharmacokinetics of the ketamine exposure (which has a peak exposure in the brain within 15 min of s.c. injection; paper in preparation).

At the end of each experiment (within 50-80 min after ketamine/vehicle injection), a blood sample $(4.5-6 \mathrm{ml})$ was taken from each rat by cardiac puncture to determine exposure to ketamine and levels of its major metabolite norketamine. Sample analysis was performed using a mass spectrometry assay by Advion Bioanalytical Labs (Quintiles, Indianapolis, IN; further details are provided in Supplementary Material).

\section{Image Preprocessing}

Preprocessing was performed as described previously (for details, see Gass et al, 2012). In brief, the EPI time series images were corrected for magnetic field $\left(\mathrm{B}_{0}\right)$ inhomogeneities using acquired FieldMap sequences (SPM8 http:// www.fil.ion.ucl.ac.uk/spm/software/spm8/). To minimize the 
effect of movement on the signal intensities, the estimated movement parameter vectors were regressed out from each voxel (FSL, version 4.1. http://www.fmrib.ox.ac.uk/fsl). Afterward, respiratory and cardiac signals were filtered out from each voxel using Aztec software (van Buuren et al, 2009). A slice-timing correction was then applied to the images using SPM8. We used this order of preprocessing steps as it has been shown to be the most optimal in terms of minimizing temporal standard deviation (Jones et al, 2008). The time courses were then band-pass filtered (0.01$0.1 \mathrm{~Hz}$; Analysis of Functional Neuroimages (AFNI) version 2). Finally, the functional data were spatially normalized (SPM8) to a rat brain template with co-registered anatomical atlas positioned in the Paxinos stereotactic coordinate system (Schwarz et al, 2006) using a three-step process: (1) creation of a mean image from all time series and normalization of all images to this grand mean image, (2) normalization of the grand mean image to the template, and (3) normalization of all images from step 1 to the template using the transformation matrix from step (2).

\section{Region-of-Interest Correlation Analysis}

Coupling between predefined regions of interest (ROI) was assessed using two spatial sampling schemes. For the primary analysis, the brain was parcellated into 10 midline or bilateral hippocampal and cortical brain regions corresponding to established atlas structures (Schwarz et al, 2006; Figure 1). The cortical regions included infralimbic, prelimbic, orbitofrontal, cingulate (areas 1 and 2), and retrosplenial cortices; the hippocampus was subdivided into anterodorsal, posterodorsal, ventral, and subiculum/dentate gyrus parts of the hippocampus (Gass et al, 2012). In a secondary analysis, 19 midline or bilateral $0.6 \times 0.6 \times 0.8 \mathrm{~mm}$ ROIs centered on specified stereotactic coordinates were defined as in our previous characterization of functional connectivity (Schwarz et al, 2013). This enabled the conclusions of the first analysis to be tested with a different (sparse) spatial sampling scheme and provides a direct link to the previous work.

The mean time course from each ROI was extracted for each rs-fMRI time series. All-pairs correlation coefficients were then calculated, and converted to z-scores $z(r)$ using Fisher's $r$-to- $z$ transformation $(0.5 \times \ln [(1+r) /(1-r)])$. Within each subject, the 15- and 30-min post-injection values of $z(r)$ were each normalized to the corresponding pre-injection baseline values: $\delta z_{15}=z_{15}-z_{\text {pre }}$ and $\delta z_{30}=$ $z_{30}-z_{\text {pre }}$, using each animal as its own within-scanning session control in order to maximize sensitivity to acute connectivity changes following compound injection.

To assess the dose-response effect of ketamine, each ROIROI pair in the resulting $\delta z$ matrices was analyzed across the two post-injection time points and the four treatment conditions using an ANOVA model with dose $(0,5,10$, $25 \mathrm{mg} / \mathrm{kg}$ ketamine) and time point (15- and 30-min post-injection) as factors. A false discovery rate correction of $q=0.05$ was applied to accommodate the multiple ROI pairs tested.

Further, pharmacokinetic-pharmacodynamic (PK-PD) relationships between ketamine plasma levels and changes in connectivity were assessed by fitting an $E_{\max }$ model $\left(\delta z=\delta z_{\min }+\left(\delta z_{\max }-\delta z_{\min }\right) /\left(1+10^{(\log (\mathrm{EC} 50)-[\mathrm{ket}])}\right)\right.$ to keta-
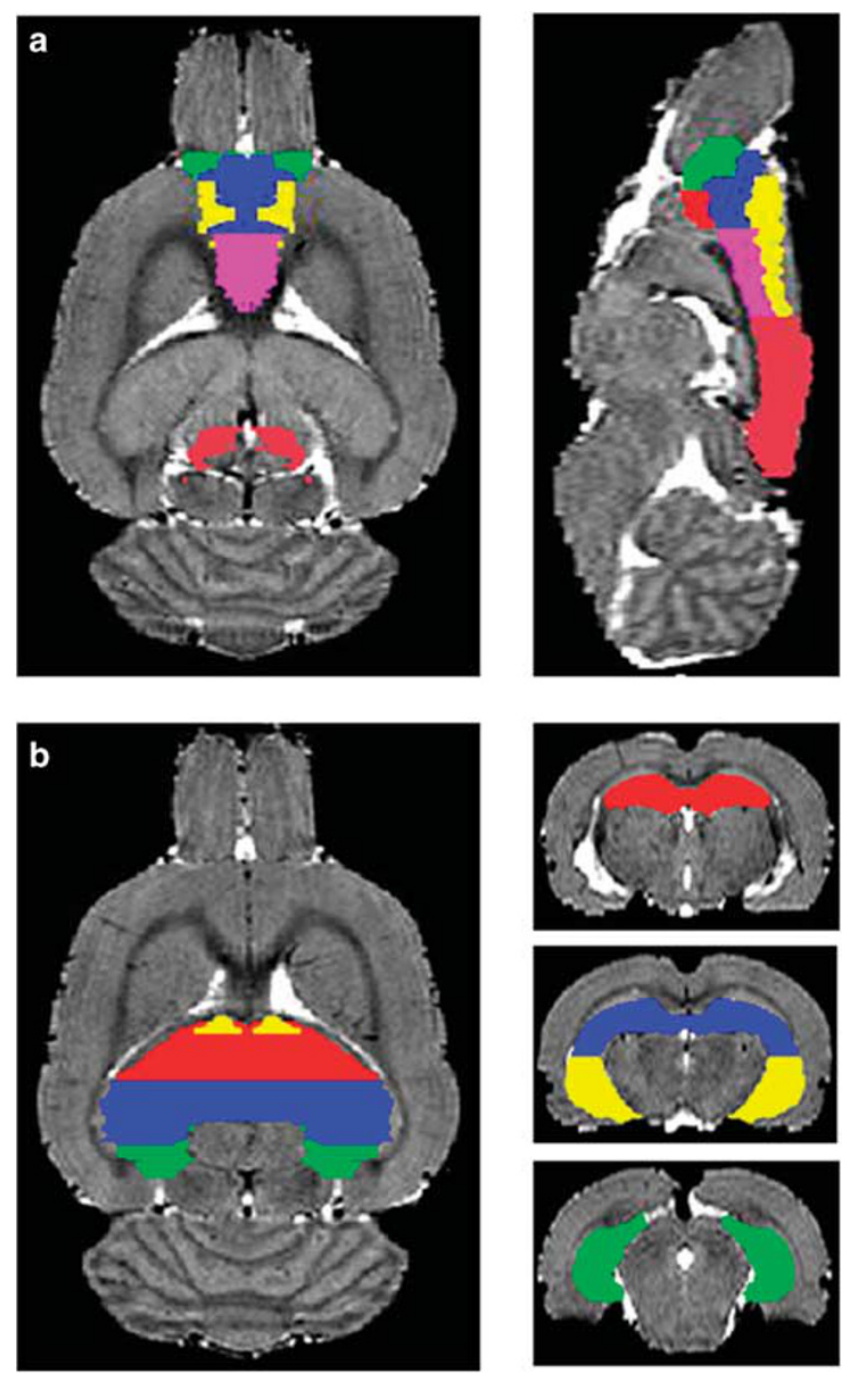

Figure I Brain masks used in ROl-ROI and seed-based analyses. Color coding: (a) red - infralimbic cortex; blue _ prelimbic cortex; green —orbitofrontal cortex; yellow - cingulate cortex, area I; magenta_cingulate cortex area 2; pink - retrosplenial cortex. (b) Red-anterodorsal hippocampus; blue-posterodorsal hippocampus; green-subiculum/dentate gyrus; yellow-ventral hippocampus.

mine concentrations ([ket]) and $\delta z$ values. A robust fit was not achieved for all ROI pairs; values from selected successful fits are reported to illustrate the consistency between doseand exposure-response profiles. Plasma ketamine levels were not corrected for the time difference between PK sample measurement and the rs-fMRI data acquisition.

\section{Seed Region Analyses}

The extracted time courses of the prefrontal (infralimbic, prelimbic, and orbitofrontal) and all hippocampal regions were used for seed-based functional connectivity analysis (SPM8). A mean time course of the seed region was extracted from each normalized, unsmoothed time series; then the data were smoothed by $0.8 \mathrm{~mm}$ (approximately two voxels in-plane). Correlation coefficients $r$ were calculated for the extracted time courses voxel-wise and transformed 
Table I Ketamine and Norketamine Concentrations Measured in Plasma by Experimental Group

\begin{tabular}{|c|c|c|}
\hline \multirow[t]{2}{*}{ Experimental group } & \multicolumn{2}{|c|}{ Mean $[S D]$ (min-max) plasma concentration (ng/ml) } \\
\hline & Ketamine & Norketamine \\
\hline $5 \mathrm{mg} / \mathrm{kg}$ & $282.33[164.52](\mid 31.99-637.59)$ & $305.03[172.06](139.46-659.58)$ \\
\hline $10 \mathrm{mg} / \mathrm{kg}$ & 601.81 [181.83] (391.56-893.39) & $527.72[259.08](329.13-1065.74)$ \\
\hline
\end{tabular}

a $5 / 9$ animals had ketamine levels below quantifiable level (BQL) of $1.00 \mathrm{ng} / \mathrm{ml}$.

b6/9 animals had norketamine levels below quantifiable level (BQL) of $1.00 \mathrm{ng} / \mathrm{ml}$.

to Fisher $\mathrm{z}$-scores as above. Next, each of the post-injection $\mathrm{z}$-scores maps was normalized to pre-injection baseline by subtracting the pre-injection $\mathrm{z}$-value from each corresponding voxel (creating $\delta z$ maps). These $\delta \mathrm{z}$ maps were fed into two second level analyses: (1) an ANOVA analysis using a contrast $[-3,-1,1,3]$ to assess dose response, and (2) a regression analysis using individual subject ketamine plasma levels as predictors, to assess dependence on peripheral drug exposure. These analyses were performed for each of the $\delta z_{15}$ and $\delta z_{30}$ maps.

The obtained statistic images were cluster corrected for multiple comparisons using FSL (height thresholds: $t=2.449$ for ANOVA; $t=2.441$ for regression analysis; $p_{\text {cluster }}=0.01$ ).

\section{Effect of Ketamine on Cardiac Frequency}

To evaluate potential confounding effects on functional connectivity because of changes in heart rate, we calculated mean cardiac frequencies over time windows corresponding to the three rs-fMRI acquisitions. First, the cardiac data were band-pass filtered $(2.5-6.0 \mathrm{~Hz})$ and Fourier transformed. The resulting spectra showing the cardiac frequency distribution were Gauss-fitted to extract representative mean values. The calculated mean cardiac frequencies were analyzed using a general linear model (GLM) for repeated measurements with dose as betweensubject factor. The repeated-measures GLM did not show a significant dose effect $(p=0.493)$. Also post-hoc contrasts of the cardiac mean frequencies for the different ketamine doses were not significant compared with saline.

\section{RESULTS}

\section{Ketamine Plasma Concentrations}

Ketamine plasma levels evidenced a linear dependence on dose (Table 1). In the vehicle group, concentrations were below the quantifiable limit $(1 \mathrm{ng} / \mathrm{ml})$ in 5/9 animals. Plasma levels of the major metabolite, norketamine, also increased linearly with dose and were highly correlated with ketamine levels $\left(r^{2}=50 \%\right)$.

\section{ROI-ROI Correlations}

We first examined the effects of ketamine on functional connectivity using the set of predefined atlas ROIs. The
ANOVA analysis over each ROI pair (Figure 2a) revealed significant effects of dose on connectivity that involved (1) connections within prefrontal and cingulate regions and (2) antero-posterior connections from hippocampal regions and the retrosplenial cortex to prefrontal and cingulate regions. Overall, the strongest effects were observed between different regions of the prefrontal and cingulate cortices, and between the retrosplenial cortex and the cingulate cortex area 2. Dose-dependent alterations were observed between all prefrontal and cingulate cortex pairs (with the exception of the infralimbic cortex to cingulate cortex area 1 connection). A second main feature we observed was an altered connectivity between the subiculum/dentate gyrus of the hippocampus and three prefrontal regions (infralimbic cortex, orbitofrontal cortex, and cingulate cortex area 2). Finally, significant effects of dose were also observed between the infralimbic cortex and both the retrosplenial cortex and posterodorsal hippocampus. The effect of post-injection time point (15 or $30 \mathrm{~min}$ ) was not significant for any ROI pair.

In all ROI pairs exhibiting a significant effect of dose, the effect of ketamine manifested as an increased correlation strength at both time points, although the magnitude and profile of the dose-response relationships varied across region pairs (Figure 2b). In some cases, near maximal connectivity change was observed at the $5 \mathrm{mg} / \mathrm{kg}$ dose (eg, prelimbic to infralimbic cortex, prelimbic to orbitofrontal cortex), whereas in others the effect increased more strongly with dose, with the connectivity change at $25 \mathrm{mg} / \mathrm{kg}$ substantially greater than those at the lower doses (eg, prelimbic to cingulate cortex area 2, subiculum/dentate gyrus to orbitofrontal cortex). Figure $2 c$ illustrates, in an anatomically anchored node-to-node view, the ROI-ROI pairs exhibiting a significant effect of ketamine dose on functional connectivity.

$\mathrm{PK} / \mathrm{PD}$ modeling revealed exposure-response relationships consistent with the dose-response behavior. Regions with connectivity changes that were near-maximal at the $5 \mathrm{mg} / \mathrm{kg}$ dose exhibited $E_{\max }$ model fits that approached a plateau at the higher plasma ketamine concentrations (eg, prelimbic to infralimbic cortex (Figure 3a); $\log ($ EC50) $\sim 2.2-$ $2.4, \mathrm{EC}_{50}=166 \mathrm{ng} / \mathrm{ml}$ at $15 \mathrm{~min}$ and $234 \mathrm{ng} / \mathrm{ml}$ at $30 \mathrm{~min}$ ). Conversely, regions with more steeply increasing connectivity changes as a function of dose exhibited $E_{\max }$ curves that were further right-shifted (eg, infralimbic to cingulate cortex area 2 (Figure 3b); $\log (\mathrm{EC} 50) \sim 3.4, \mathrm{EC}_{50}=2730 \mathrm{ng} /$ $\mathrm{ml}$ at $15 \mathrm{~min}$ and $2627 \mathrm{ng} / \mathrm{ml}$ at $30 \mathrm{~min}$ ). 

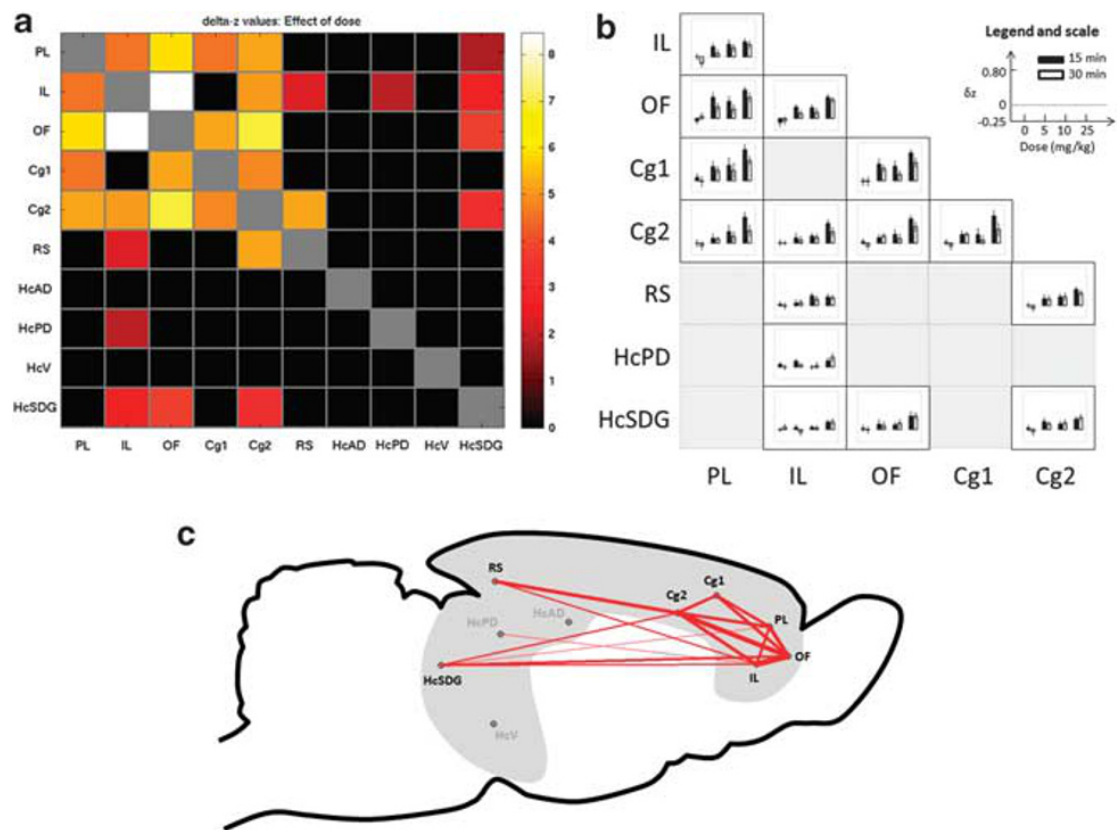

Figure 2 (a) ROI-ROI pairs for which the main effect of dose was significant (two-way ANOVA (dose and time point as factors); FDR: $q<0.05$ ); color bar indicates statistical significance as - $\log _{10}(\mathrm{p})$; black squares: ROI pairs not achieving statistical significance. (b) ROI-ROI pair dose-response profiles for correlation coefficient $\delta$ z changes; shown only for cells identified as significant. (c) Sagittal view of the node-to-node connections within the hippocampalprefrontal system exhibiting a significant effect of ketamine dose (cf. (a)). Thicker lines indicate statistically stronger effects. CgI, cingulate cortex, area I; Cg2, cingulate cortex, area 2; HcAD, hippocampus, anterodorsal; HcPD, hippocampus, posterodorsal; HcSDG, hippocampus, subiculum and dentate gyrus; HcV, hippocampus, ventral; IL, infralimbic cortex; OF, orbitofrontal cortex; PL, prelimbic cortex; RS, retrosplenial cortex.

Results with the coordinate ROI set $(19 \times 19$ ROIs $)$ were consistent with those described above, namely a widespread effect of dose corresponding to increased functional connectivity within the prefrontal cortex and in more specific connections between hippocampal and prefrontal regions (Supplementary Material).

\section{Whole-Brain Seed Region Analyses}

We next performed whole-brain voxel-wise seed region analyses to assess the effects of ketamine, with respect to pre-defined hippocampal and prefrontal seeds (Table 2). For most of the seeds, the strongest modulatory effects of ketamine were localized to the prefrontal cortex.

Among the hippocampal seeds, the strongest finding was an increased connectivity of the subiculum/dentate gyrus with prefrontal (prelimbic cortex, orbitofrontal cortex, and cingulate cortex area 1) and insular cortices at both postinjection time points. This was observed with respect to both dose and ketamine plasma concentrations (Figure 4a). For the other hippocampal regions, significant changes in connectivity were stronger at 30 -min post-injection. The anterodorsal and posterodorsal hippocampi had increased connectivity with prelimbic, retrosplenial, and insular cortices ( $v s$ both dose and ketamine plasma levels), and the ventral hippocampus showed increased connectivity with the caudate-putamen as a function of ketamine plasma levels at 30 min only.

Among the prefrontal regions, the strongest result was observed with respect to infralimbic cortex and comprised an increased connectivity with orbital cortex and cingulate cortex area 2 at $15 \mathrm{~min}$, with the prelimbic cortex at both time points and with the postsubiculum at 30-min post-injection. A similar increased connectivity with prefrontal cortex was obtained for the orbitofrontal seed and prelimbic seeds.

\section{DISCUSSION}

We demonstrated that acute ketamine challenge induces doseand exposure-dependent increases in functional connectivity within the HC-PFC system in the rat brain. Specifically, we observed (1) an increased connectivity between most pairs of regions within the prefrontal and cingulate cortices, and (2) an increased anterior-posterior connectivity between the retrosplenial cortex and posterior regions of the hippocampus, and regions in the prefrontal cortex.

Although rs-fMRI is well established in humans and has been shown to be sensitive to pharmacological modulation, consistent intrinsic connectivity networks have only recently been demonstrated in the rat, and pharmacological effects on rs-fMRI are only beginning to be characterized in the rodent (Gass et al, 2012). This study moves this field forward in several respects. First, we elucidated the effects of ketamine-one of the most widely used compounds in behavioral research and pharmacological screening-on functional connectivity in the rat brain. This provides a preclinical analog of rs-fMRI studies that are increasingly performed in humans and will help to determine the translational viability of functional connectivity measures in this pharmacological model. Second, we evaluated a range of behaviorally active doses and assessed compound 


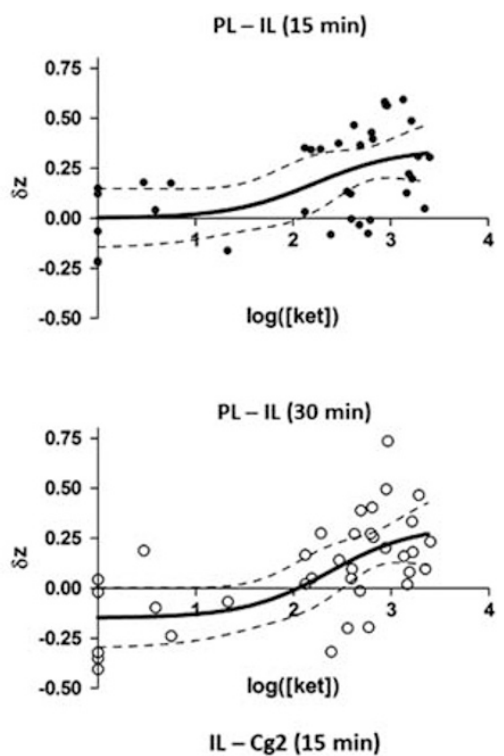

b
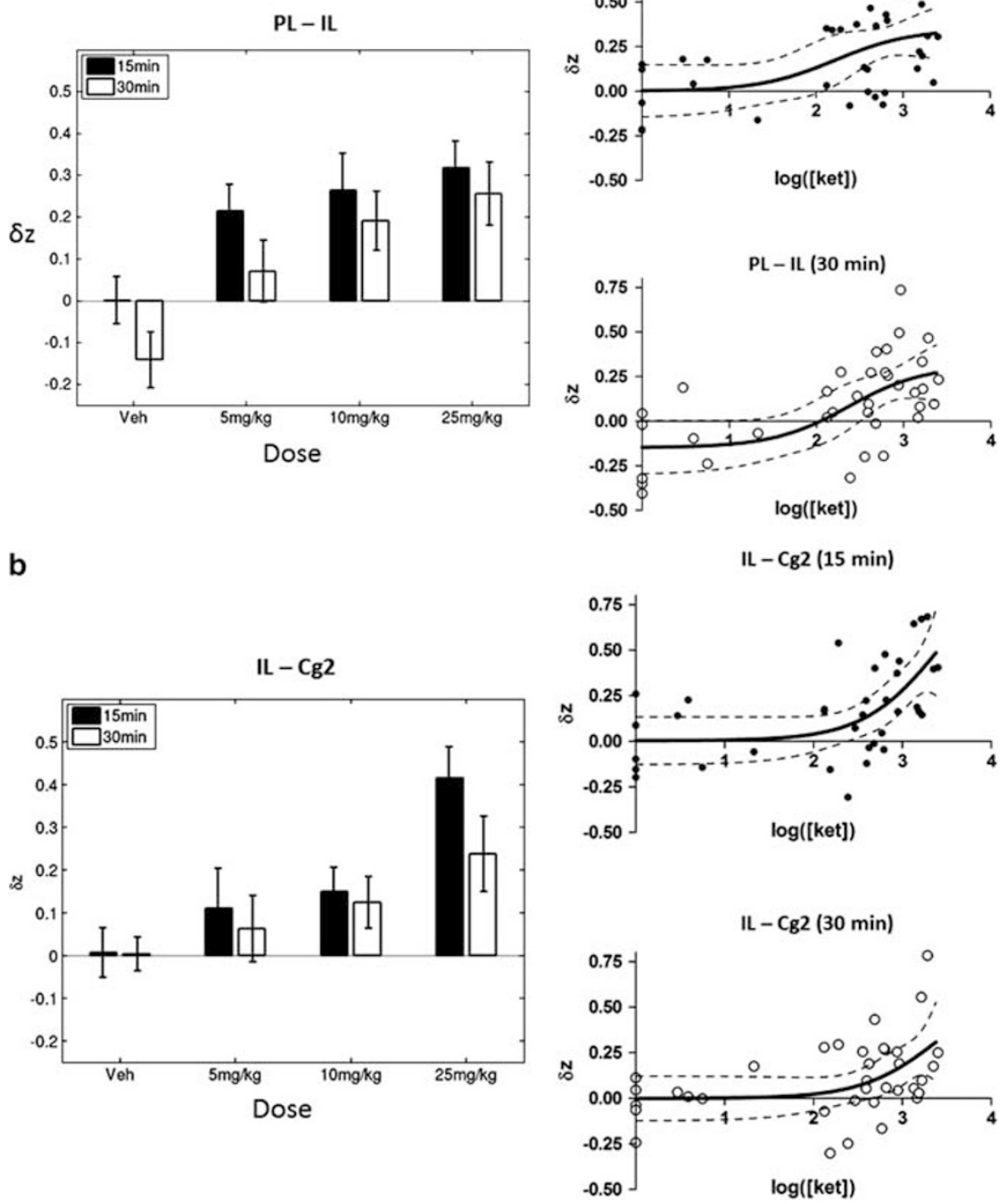

Figure 3 Illustration of consistent dose-response and exposure-response relationships. (a) Change in normalized correlation coefficients $(\delta z)$ between prelimbic (PL) and infralimbic (IL) cortices across treatment conditions (left) and ketamine exposure levels (right) (I5- and 30-min post-injection). (b) Change in normalized correlation coefficients $(\delta z)$ between IL cortex and cingulate cortex area 2 (Cg2) across treatment conditions (left) and ketamine exposure levels (right) (15- and 30-min post-injection).

exposure in plasma, enabling dose-response and PK-PD relationships to be evaluated. This is standard practice in most pharmacological assays but remains under-utilized in fMRI studies.

The connectivity changes we observed were in region pairs consistent with the strongest connections within this network reported in our previous study (Schwarz et al, 2013); namely, between subregions of the prefrontal and cingulate cortices and between the posterior (subiculum) region of the hippocampus and the prefrontal cortex. This latter functional coupling matches the anatomical projection reaching from the posterior CA1 and subiculum regions of the hippocampus to the infralimbic, prelimbic, and anterior cingulate cortices (Godsil et al, 2013). We also applied the same ANOVA model to the set of coordinatebased ROIs used in our previous study (Schwarz et al, 2013), and found very similar results, with the strongest emergent finding being a widespread dose-dependent increase in connectivity between anterior seeds with more restricted modulation of correlations between the hippocampus and prefrontal cortex. Although obtained from the same data set and thus not an independent sample, this secondary analysis nevertheless confirms that the primary findings of this study are also observed with a sparse and more focal anatomical sampling, and thus are not an artifact of our particular choice of ROIs.

Our finding of increased functional coupling following ketamine infusion is directly consistent with a recent study (Driesen et al, 2013) of ketamine effects on rs-fMRI in humans, where a widespread increase in brain connectivity (quantified as overall node connectivity) was reported, although HC-PFC interactions were not specifically examined. Two other recent studies (Niesters et al, 2012; Scheidegger et al, 2012) examining ketamine effects on 


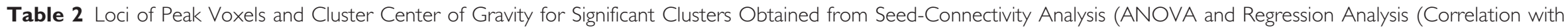
Ketamine Exposure)) at 15- and 30-Min Post-Injection

\begin{tabular}{|c|c|c|c|c|c|c|c|c|c|c|c|c|c|c|c|}
\hline \multirow[t]{2}{*}{ Seed region } & \multirow[t]{2}{*}{ Model } & \multirow[t]{2}{*}{$\begin{array}{l}\text { Time } \\
\text { point }\end{array}$} & \multirow[t]{2}{*}{ Cluster } & \multirow{2}{*}{$\begin{array}{l}\text { Number of } \\
\text { voxels in } \\
\text { cluster }\end{array}$} & \multirow[t]{2}{*}{$p$-value } & \multirow[t]{2}{*}{$-\operatorname{LOG}_{10}(P)$} & \multirow[t]{2}{*}{$T_{\text {MAX }}$} & \multicolumn{3}{|c|}{$\begin{array}{l}\text { Peak voxel } \\
\text { of cluster }\end{array}$} & \multicolumn{3}{|c|}{$\begin{array}{l}\text { Cluster center } \\
\text { of gravity }\end{array}$} & \multicolumn{2}{|c|}{$\begin{array}{l}\text { Anatomical } \\
\text { localization }\end{array}$} \\
\hline & & & & & & & & $\begin{array}{c}X(M-L) \\
(m m)\end{array}$ & $\begin{array}{c}Y(D-V) \\
(\mathbf{m m})\end{array}$ & $\begin{array}{c}Z(\mathbf{A}-P) \\
(\mathrm{mm})\end{array}$ & $\begin{array}{c}X(M-L) \\
(\mathrm{mm})\end{array}$ & $\begin{array}{c}Y(D-V) \\
(\mathbf{m m})\end{array}$ & $\begin{array}{c}\mathrm{Z}(\mathrm{A}-\mathrm{P}) \\
(\mathrm{mm})\end{array}$ & $\begin{array}{l}\text { Peak } \\
\text { voxel }\end{array}$ & $\begin{array}{c}\text { Cluster center } \\
\text { of gravity }\end{array}$ \\
\hline \multirow[t]{9}{*}{ HCAD } & Dose (ANOVA) & $15 \mathrm{~min}$ & - & - & - & - & - & - & - & - & - & - & - & - & - \\
\hline & & $30 \mathrm{~min}$ & 3 & 311 & 0.0004 & 3.45 & 6.31 & 2.8 & -3.87 & 1.52 & 1.9 & -4.45 & 3.37 & $\mathrm{CPu}$ & $\mathrm{Cl}$ \\
\hline & & & 2 & 181 & 0.0096 & 2.02 & 5.68 & -4.87 & -6.43 & 2.25 & -4.34 & -5.47 & 2.52 & $\mathrm{DI}$ & DI \\
\hline & & & 1 & 143 & 0.0285 & 1.54 & 4.33 & 3.53 & -0.59 & -5.41 & 0.44 & -0.67 & -6.0 & VI & RSD \\
\hline & PK (regression) & $15 \mathrm{~min}$ & 2 & 99 & 0.0177 & 1.75 & 4.01 & -4.5 & -1.68 & 3.35 & -4.03 & -1.52 & 2.99 & MI & $\mathrm{Fr} 3$ \\
\hline & & & I & 97 & 0.0195 & 1.71 & 3.42 & 3.89 & -3.14 & 4.44 & 4.9 & -2.42 & 2.37 & MI & SIDZ \\
\hline & & $30 \mathrm{~min}$ & 3 & 159 & 0.0078 & 2.11 & 5.51 & 3.89 & -0.59 & -5.41 & 0.78 & -0.63 & -5.86 & VI & RSD \\
\hline & & & 2 & 148 & 0.0113 & 1.95 & 5.72 & -4.87 & -6.43 & 2.25 & -4.72 & -6.43 & 1.29 & DI/AID & DI \\
\hline & & & 1 & 107 & 0.0492 & 1.31 & 4.33 & 3.53 & -4.6 & 4.08 & 2.68 & -3.97 & 4.36 & AID & AIVIAID \\
\hline \multirow[t]{8}{*}{ HcPD } & Dose (ANOVA) & $15 \mathrm{~min}$ & I & 183 & 0.0010 & 3.02 & 4.68 & 3.16 & -1.68 & -1.03 & 4.69 & -2.46 & -0.62 & $\mathrm{SIHL}$ & SIFL/SIDZ \\
\hline & & $30 \mathrm{~min}$ & 3 & 572 & $1.4 \mathrm{e}-05$ & 4.85 & 5.66 & 0.97 & -0.95 & 4.08 & 0.64 & -4.1 & 3.21 & M2 & PL \\
\hline & & & 2 & 280 & 0.0027 & 2.57 & 5.85 & -4.5 & -6.06 & 1.89 & -4.0 & -5.53 & 2.23 & $\mathrm{Dl}$ & $\mathrm{Gl}$ \\
\hline & & & I & 278 & 0.0028 & 2.55 & 4.34 & -5.96 & -3.51 & -1.4 & -5.31 & -2.94 & -1.48 & SIBF & SIBF \\
\hline & PK (regression) & $15 \mathrm{~min}$ & - & - & - & - & - & - & - & - & - & - & - & - & - \\
\hline & & $30 \mathrm{~min}$ & 3 & 500 & $2.95 \mathrm{e}-05$ & 4.53 & 4.98 & -2.31 & -1.68 & 4.44 & 0.76 & -3.5 & 3.61 & $M 2$ & $P L$ \\
\hline & & & 2 & 427 & 0.0001 & 3.96 & 5.68 & -4.87 & -6.06 & 1.89 & -4.16 & -5.97 & 1.81 & $\mathrm{Gl}$ & $\mathrm{AID} / \mathrm{VCl}$ \\
\hline & & & I & 192 & 0.0149 & 1.83 & 4.45 & -0.85 & -2.41 & -0.67 & -0.04 & -2.34 & -0.54 & $\mathrm{Cg} 2 / \mathrm{Cg} 1$ & $\mathrm{Cg} 2 / \mathrm{Cgl}$ \\
\hline \multirow[t]{11}{*}{ HcSDG } & Dose (ANOVA) & $15 \mathrm{~min}$ & 5 & 274 & 0.0008 & 3.08 & 4.29 & 0.24 & -4.6 & 4.81 & 0.57 & -3.84 & 3.89 & MO & $P L$ \\
\hline & & & 4 & 231 & 0.0024 & 2.61 & 4.77 & 2.8 & -2.41 & -0.67 & 2.75 & -2.18 & -0.56 & $\mathrm{SIHL}$ & SIHL \\
\hline & & & 3 & 222 & 0.0031 & 2.51 & 4.64 & -2.68 & -4.24 & 0.42 & -1.96 & -2.23 & 1.65 & $\mathrm{CPu}$ & MI/M2 \\
\hline & & & 2 & 139 & 0.0316 & 1.5 & 4.99 & -3.04 & -3.87 & 4.81 & -3.63 & -4.78 & 3.1 & DLO & $\mathrm{Dl}$ \\
\hline & & & । & 128 & 0.0442 & 1.35 & 5.46 & -6.69 & -3.87 & -2.86 & -6.41 & -3.96 & $-2.7 \mid$ & SIUIP & SIUIP \\
\hline & & $30 \mathrm{~min}$ & 3 & 610 & $5.3 e-06$ & 5.28 & 6.43 & -4.14 & -5.33 & 2.25 & -1.68 & -4.85 & 2.88 & $\mathrm{Gl}$ & $\mathrm{Cl}$ \\
\hline & & & 2 & 468 & $5.91 \mathrm{e}-05$ & 4.23 & 4.85 & -3.41 & -1.68 & -2.86 & -4.44 & -2.15 & -1.37 & SITr & SIDZ \\
\hline & & & 1 & 228 & 0.0068 & 2.17 & 4.03 & 2.8 & -1.32 & 1.52 & 3.04 & -0.98 & -0.46 & MI & SIHL \\
\hline & PK (regression) & $15 \mathrm{~min}$ & 2 & 749 & $5.96 \mathrm{e}-08$ & 7.22 & 5.01 & -3.77 & -5.7 & 1.89 & -0.83 & -3.18 & 2.39 & $\mathrm{DCl}$ & $\mathrm{Cg} 2$ \\
\hline & & & 1 & 136 & 0.0329 & 1.48 & 4.18 & 2.07 & -3.14 & -1.4 & 3.93 & -2.37 & -0.33 & $\mathrm{SIHL}$ & SIFL \\
\hline & & $30 \mathrm{~min}$ & I & 1983 & $7.11 \mathrm{e}-13$ & 12.1 & 6.65 & -4.14 & -5.7 & 1.89 & -0.81 & -3.99 & 1.59 & $\mathrm{Gl}$ & $\mathrm{Cg} 2$ \\
\hline \multirow[t]{4}{*}{$\mathrm{HcV}$} & Dose (ANOVA) & $15 \mathrm{~min}$ & - & - & - & - & - & - & - & - & - & - & - & - & - \\
\hline & & $30 \mathrm{~min}$ & - & - & - & - & - & - & - & - & - & - & - & - & - \\
\hline & PK (regression) & $15 \mathrm{~min}$ & - & - & - & - & - & - & - & - & - & - & - & - & - \\
\hline & & $30 \mathrm{~min}$ & 1 & 86 & 0.0303 & 1.52 & 4.28 & -1.95 & -3.14 & -0.67 & -2.73 & -3.88 & -0.03 & $\mathrm{SIHL}$ & $\mathrm{CPu}$ \\
\hline \multirow[t]{8}{*}{ IL } & Dose (ANOVA) & $15 \mathrm{~min}$ & 2 & 3451 & $2.05 e-17$ & 16.7 & 7.79 & -1.95 & -3.87 & 4.44 & -0.81 & -2.68 & 1.22 & LO & $\mathrm{Cg} 2$ \\
\hline & & & 1 & 204 & 0.0247 & 1.61 & 4.13 & 6.45 & -2.78 & -2.49 & 6.23 & -3.9 & -3.58 & SIBF & $\mathrm{S} 2$ \\
\hline & & $30 \mathrm{~min}$ & 2 & 1200 & $2 e-09$ & 8.7 & 6.33 & -0.12 & -4.24 & 4.08 & 0.15 & -3.27 & 3.41 & PL & $P L$ \\
\hline & & & I & 688 & $2.26 \mathrm{e}-06$ & 5.64 & 5.02 & 0.6 & -0.22 & -2.13 & -2.68 & -1.21 & -1.36 & $M 2$ & $\mathrm{SIHL}$ \\
\hline & PK (regression) & $15 \mathrm{~min}$ & I & 1603 & $1.93 \mathrm{e}-13$ & 12.7 & 6.22 & -1.22 & -1.32 & 2.98 & -0.15 & -2.83 & 2.56 & $M 2$ & PL \\
\hline & & $30 \mathrm{~min}$ & 3 & 1027 & $4.52 \mathrm{e}-10$ & 9.34 & 5.61 & -0.12 & -4.24 & 4.08 & -0.04 & -3.17 & 3.2 & $P L$ & $P L$ \\
\hline & & & 2 & 144 & 0.0262 & 1.58 & 5.84 & -2.68 & -3.87 & -6.51 & -2.65 & -3.38 & -6.43 & SuG & Post \\
\hline & & & 1 & 133 & 0.0366 & 1.44 & 3.77 & -3.41 & -0.22 & 1.52 & -2.84 & -0.69 & 0.27 & MI & SIHL \\
\hline
\end{tabular}


Table 2 (Continued)

\begin{tabular}{|c|c|c|c|c|c|c|c|c|c|c|c|c|c|c|c|}
\hline \multirow[t]{2}{*}{ Seed region } & \multirow[t]{2}{*}{ Model } & \multirow[t]{2}{*}{$\begin{array}{l}\text { Time } \\
\text { point }\end{array}$} & \multirow[t]{2}{*}{ Cluster } & \multirow{2}{*}{$\begin{array}{l}\text { Number of } \\
\text { voxels in } \\
\text { cluster }\end{array}$} & \multirow[t]{2}{*}{$p$-value } & \multirow[t]{2}{*}{$-\operatorname{LOG}_{10}(\mathrm{P})$} & \multirow[t]{2}{*}{$T_{\text {MAX }}$} & \multicolumn{3}{|c|}{$\begin{array}{l}\text { Peak voxel } \\
\text { of cluster }\end{array}$} & \multicolumn{3}{|c|}{$\begin{array}{l}\text { Cluster center } \\
\text { of gravity }\end{array}$} & \multicolumn{2}{|c|}{$\begin{array}{l}\text { Anatomical } \\
\text { localization }\end{array}$} \\
\hline & & & & & & & & $\begin{array}{c}X(M-L) \\
(\mathrm{mm})\end{array}$ & $\begin{array}{c}Y(D-V) \\
(\mathrm{mm})\end{array}$ & $\begin{array}{l}\text { Z (mm) } \\
\text { Z(A-P) }\end{array}$ & $\begin{array}{c}X(M-L) \\
(\mathrm{mm})\end{array}$ & $\begin{array}{c}Y(D-V) \\
(\mathrm{mm})\end{array}$ & $\begin{array}{c}\text { Z (A-P) } \\
(\mathrm{mm})\end{array}$ & $\begin{array}{l}\text { Peak } \\
\text { voxel }\end{array}$ & $\begin{array}{c}\text { Cluster center } \\
\text { of gravity }\end{array}$ \\
\hline \multirow[t]{6}{*}{ OF } & Dose (ANOVA) & $15 \mathrm{~min}$ & 1 & 2927 & $1.52 \mathrm{e}-15$ & 14.8 & 7.13 & 0.24 & -4.24 & 2.62 & 0.01 & -2.8 & 1.53 & $\mathrm{PL}$ & $\mathrm{Cg} 2$ \\
\hline & & $30 \mathrm{~min}$ & । & 1794 & $3.05 e-12$ & 11.5 & 5.5 & 0.24 & -3.87 & 2.62 & -0.29 & -2.91 & 1.38 & $P L$ & $\mathrm{Cg} 2$ \\
\hline & PK (regression) & $15 \mathrm{~min}$ & 2 & 2083 & $3.02 \mathrm{e}-14$ & 13.5 & 6.15 & -4.14 & -6.06 & 1.89 & 0.01 & -2.86 & 2.19 & DI & $\mathrm{Cg} 2$ \\
\hline & & & 1 & 162 & 0.0326 & 1.49 & 4.34 & -2.68 & -0.22 & -4.68 & -2.74 & -0.39 & -4.6 & $\mathrm{~V} 2 \mathrm{ML}$ & V2ML \\
\hline & & $30 \mathrm{~min}$ & 2 & 2439 & $8.28 \mathrm{e}-14$ & 13.1 & 6.46 & 0.24 & -3.87 & 2.62 & -0.46 & -2.72 & 1.28 & $P L$ & $\mathrm{Cg} 2$ \\
\hline & & & 1 & 285 & 0.0052 & 2.29 & 4.67 & 5.35 & -3.14 & -7.97 & 3.95 & -3.39 & -7.19 & V2L & Post \\
\hline \multirow[t]{9}{*}{ PL } & Dose (ANOVA) & $15 \mathrm{~min}$ & 3 & 2825 & $5.77 \mathrm{e}-15$ & 14.2 & 6.5 & 0.6 & -4.24 & 2.98 & 0.11 & -2.49 & 2.18 & $P L$ & $\mathrm{Cg} 2$ \\
\hline & & & 2 & 225 & 0.0176 & 1.75 & 5.96 & -7.06 & -3.87 & -2.13 & -6.59 & -4.19 & -1.99 & SIUIP & SIBF \\
\hline & & & 1 & 176 & 0.0466 & 1.33 & 5.6 & -7.06 & -6.43 & -6.51 & -6.12 & -4.04 & -7.29 & PRh & V2L \\
\hline & & $30 \mathrm{~min}$ & 3 & 1035 & $6.16 \mathrm{e}-09$ & 8.21 & 5.96 & 0.6 & -4.6 & 2.98 & -0.1 & -3.37 & 3.7 & PL/L & $P L$ \\
\hline & & & 2 & 612 & $3.76 \mathrm{e}-06$ & 5.43 & 5.82 & -2.68 & -0.59 & 1.16 & -0.46 & -0.44 & -0.99 & MI & M2 \\
\hline & & & I & 194 & 0.0131 & 1.88 & 4.36 & -6.69 & -3.14 & -2.49 & -6.45 & -3.58 & -1.97 & SIBF & SIBF \\
\hline & PK (regression) & $15 \mathrm{~min}$ & I & 2105 & $3.75 \mathrm{e}-14$ & 13.4 & 5.5 & -4.14 & -6.06 & 1.89 & -0.02 & -2.61 & 2.57 & $\mathrm{DI}$ & PL \\
\hline & & & I* & 209 & 0.0114 & 1.94 & 4.37 & 0.6 & -3.87 & -2.13 & -0.49 & -6.58 & -2.2 & CA3 & AM \\
\hline & & $30 \mathrm{~min}$ & I & 2262 & $4.1 e-14$ & 13.4 & 7.03 & 2.07 & -3.51 & 4.44 & -0.25 & -2.34 & 2.1 & CI/LO & $\mathrm{Cg} / / \mathrm{Cg} 2$ \\
\hline
\end{tabular}

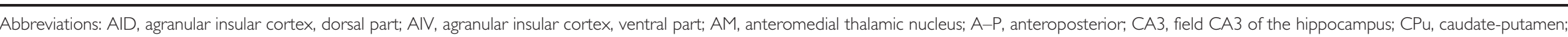

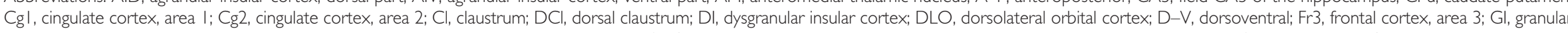

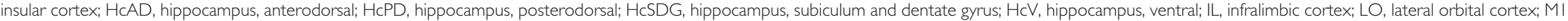

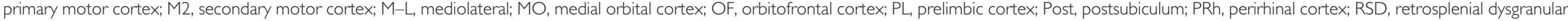

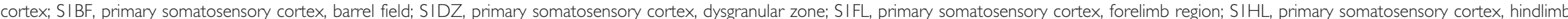

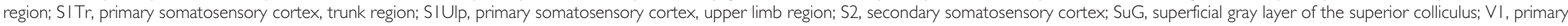
visual cortex; V2L, secondary visual cortex, lateral area; V2ML, secondary visual cortex, mediolateral area; V2MM, secondary visual cortex, mediomedial area; VCl, ventral claustrum.

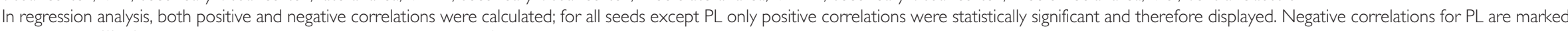
with asterisk (*). Coordinates are given in the stereotactic space of Paxinos and Watson. 

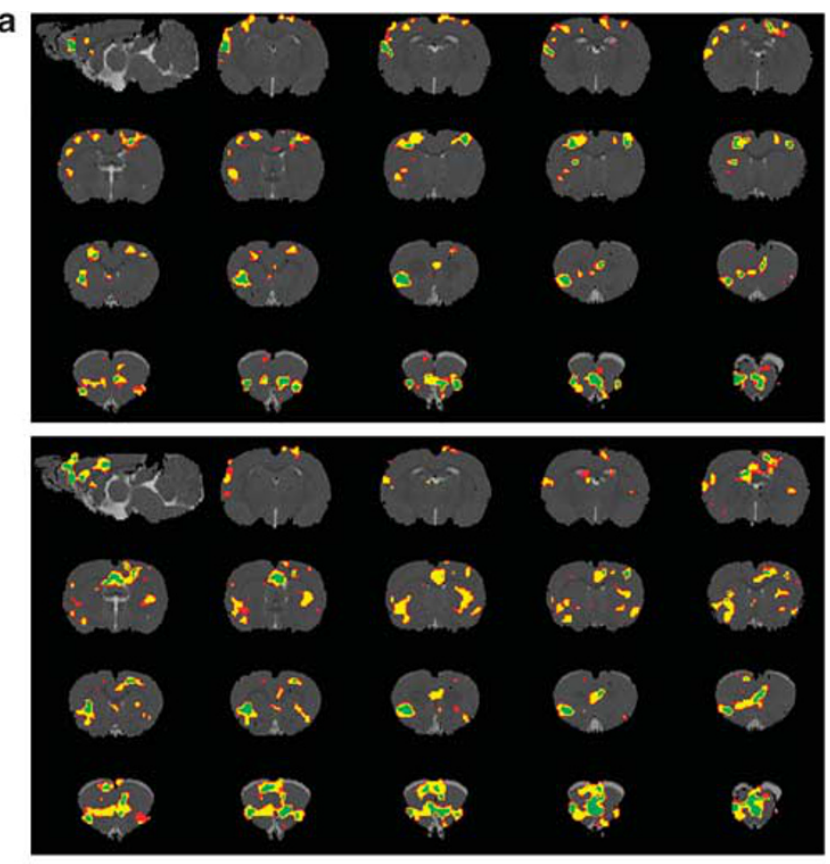

b
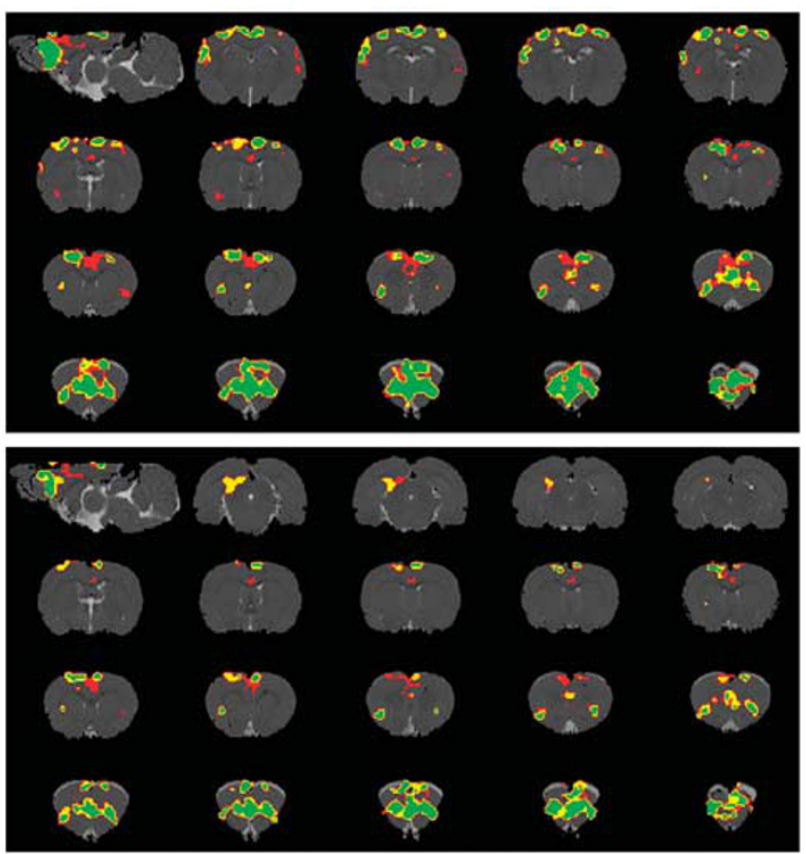

Figure 4 Maps of functional connectivity for (a) subiculum/dentate gyrus; (b) infralimbic cortex. For both (a) and (b) upper panel represents ANOVA dose-response analysis, lower panel-positive correlation with ketamine plasma levels. Coronal slice coverage in z-bregma: (a) $-2.4 \div 4.8 \mathrm{~mm}$ for both upper and lower panels, (b) $-2.4 \div 4.8 \mathrm{~mm}$ for upper panel; $-6.4 \div-5.2 \mathrm{~mm}$ (upper row) and $-0.8 \div 4.8 \mathrm{~mm}$ (from the second to the fourth rows) for lower panel. Color coding: red-15-min post-injection, yellow-30-min post-injection, green-overlap in correlation between 15- and 30-min post-injection. Maps are thresholded at $p=0.01$

rs-fMRI in humans were not methodologically consistent with our study. In one (Scheidegger et al, 2012), connectivity changes were assessed $24 \mathrm{~h}$ following cessation of ketamine infusion, for direct comparison with clinical studies in treatment-resistant depression but quite different to our paradigm in which connectivity changes were assessed during the maximal period of ketamine exposure. In the other (Niesters et al, 2012) a different analysis approach (dual regression) was used and connectivity changes with respect to visual and somatosensory networks, not assessed in our work, were reported.

Interestingly, both the increased intra-prefrontal and HCPFC connectivities are opposite to the pattern seen at rest in paranoid schizophrenic patients (Rotarska-Jagiela et al, 2010; Zhou et al, 2008). This finding argues against a simplistic interpretation of acute ketamine challenge as a 'schizophrenia model' at the brain system level and favors a more subtle interpretation. As ketamine acutely induces aberrant glutamate cycling and release, it might more specifically model hyperglutamatergic states/traits of schizophrenia. Indeed, some, but not all, patients exhibit elevated glutamate levels-a neurobiological feature that is associated with response to standard dopaminergic treatments (Egerton et al, 2012). Elevated glutamate levels are also preferentially associated with the early stages of schizophrenia; moreover (1) the glutamine/glutamate ratio is increased in patients at the early stage but becomes lower than in healthy subjects once the disease reaches its chronic stage (Marsman et al, 2013), and (2) ketamine produces cognitive disruption that resembles the data observed in patients with prodromal stage of schizophrenia (Moore et al, 2013). Future work to understand these relationships is necessary, for example, through clinical studies of rsfMRI in early stage $v s$ chronic schizophrenic patients and characterization of genetic high-risk rodent models for schizophrenia such as copy number variant mice.

Although ketamine challenge is often interpreted in terms of glutamatergic function, we note that, at the neurochemical level, ketamine also induces elevation of glutamate and several other excitatory neurotransmitters levels, such as norepinephrine, acetylcholine, dopamine, and histamine in the HC-PFC regions (Fell et al, 2010; Kubota et al, 1999; Lorrain et al, 2003; Moghaddam et al, 1997; Sato et al, 1996), probably by blocking NMDA receptors on GABAergic interneurons and a consequent facilitation of disinhibition (Seamans, 2008) and also when binding to cholinergic, monoaminergic, nicotinic, and muscarinic receptors (Mion and Villevieille, 2013). The resulting disinhibition of cortical and hippocampal neurons drives an increased glucose utilization (Duncan et al, 1998) and BOLD image contrast in hippocampal and prefrontal regions in the rat (Chin et al, 2011).

The whole-brain seed region analyses indicated that the strongest effects on connectivity with regions in the HCPFC network were predominantly within this same network. However, several significant effects were observed between HC-PFC regions and structures outside this circuit. A region that consistently showed an increased functional coupling with this circuit was the insular cortex. Functionally, the insula is a versatile brain area involved in visceral sensation (Critchley et al, 2004), pain perception (Isnard et al, 2011), and social emotions (Immordino-Yang et al, 2009) in humans. Insular morphometric changes are consistently found in early psychosis and correlate with psychosis severity (Crespo-Facorro et al, 2000). The increased correlations observed between the insula and infralimbic cortex as well as with the hippocampal seeds in the presence 
of ketamine could reflect a modulation of the above mentioned functions: changes in body perception, analgesia, and a psychotomimetic effect, all of which are observed following ketamine infusion in humans.

In ROI pairs where the $E_{\max }$ model could be reliably estimated, we found a good correspondence between doseresponse and exposure-response relationships to ketamine. However, we found evidence that, for the doses tested here, the dose-response relationship was different for different pairs of brain regions. Many of the connections between the prefrontal/anterior cingulate subregions showed near-maximal connectivity changes at the $5 \mathrm{mg} / \mathrm{kg}$ dose. In contrast, many of the anterior-posterior connections (eg, subiculum/ dentate gyrus or cingulate cortex area 2 to more anterior ROIs) evidenced a more monotonic dose-response with maximal correlation changes observed at the $25 \mathrm{mg} / \mathrm{kg}$ dose. One limitation of the study is that the plasma samples were obtained approximately $30-45 \mathrm{~min}$ after the rs-fMRI measurements, and so the measured ketamine concentrations could be as much as an order of magnitude less than those during the first rs-fMRI time series. Nevertheless, if a wellbehaved decrease in plasma concentration for each subject is assumed, the relative forms of the exposure-response relationships we found (eg, lower exposures required to alter connectivity between prelimbic and infralimbic cortices relative to infralimbic-cingulate cortex area 2 connectivity; Figure 3) should be similar to those that would have been obtained if samples were obtained concurrently with the rs-fMRI measurements, especially as these were highly consistent with dose-response relationships in the same brain region pairs (Figure 3).

Electrophysiological measures relevant to psychiatric disorders, NMDA blockade, and the HC-PFC system suggest some possible neuronal correlates of our observations. The power of gamma oscillations $(30-80 \mathrm{~Hz})$, a ubiquitous rhythm hypothesized to integrate neural networks and to have a major role in perception, is enhanced in schizophrenic patients compared with healthy controls (Bandyopadhyaya et al, 2011). Also in human and in rat, ketamine induces an increase in baseline gamma power (Pinault, 2008), which most likely results from the blockade of NMDA receptors at GABAergic interneurons, as they have greater sensitivity to NMDA receptor antagonists than pyramidal neurons (Grunze et al, 1996). However, the increase in gamma band activity following visual processing and memory tasks is reduced in schizophrenia and following ketamine in healthy subjects (Grutzner et al, 2013), implying that while resting-state coherence may be increased, neuronal plasticity involving NMDA receptors is impaired in these key circuits (Godsil et al, 2013). Given the strong correlation between gamma band oscillations and BOLD connectivity in humans (Tagliazucchi et al, 2012), these findings may provide a neuronal underpinning for our findings in this study. Although the effect of time point (15 vs 30-min postinjection) was not significant in the ROI-ROI analysis, changes at $30 \mathrm{~min}$ were qualitatively slightly lower than those at $15 \mathrm{~min}$, very consistent with the time-profile of gamma band power changes over the visual cortex reported following $10 \mathrm{mg} / \mathrm{kg}$ ketamine challenge, which peaked at approximately $15-20 \mathrm{~min}$ and were only slightly lower by $30 \mathrm{~min}$ (Phillips et al, 2012). However, it has yet to be demonstrated more explicitly that the types of connectivity observed in our study reflect gamma activation.

It should be noted that acute and long-term effects of ketamine on functional connectivity likely differ. The delayed effects of ketamine are suggested to underlie the antidepressant action and were not directly assessed in this study. Although brain-derived neurotrophic factor (BDNF) protein translation rises in the hippocampus and cortex as fast as 30min post-ketamine injection, and BDNF is likely to be crucial for ketamine antidepressant effect (Autry et al, 2011), the improvement in mood is delayed and takes place $\sim 2 \mathrm{~h}$ after ketamine administration in depressed patients (Zarate et al, 2006), which is beyond the time points that we studied. Indeed, in contrast to the results of our study, at $24 \mathrm{~h}$ after ketamine administration a reduction of functional connectivity between the posterior cingulate cortex and dorsomedial prefrontal cortex, pregenual anterior cingulate cortex and medioprefrontal cortex was observed, opposite to the pattern observed in depressed patients (Scheidegger et al, 2012).

We additionally measured the plasma concentration of ketamine's major metabolite, norketamine, which showed a steady increase with the increasing dose and correlated with ketamine plasma levels. Norketamine has been shown to positively correlate with post-ketamine stimulus-evoked somatosensory responses (Cornwell et al, 2012). Although norketamine could also have some effects on resting-state brain connectivity, future studies should examine closer its neural effects as well as its further metabolite dehydronorketamine.

This study was performed using light medetomidine anesthesia, raising the possibility of a confounding interaction with ketamine. It is known that alpha-2 adrenoreceptor agonists are able to reduce the hyperadrenergic state produced by ketamine (Levanen et al, 1995). However, medetomidine is widely used in a number of laboratories for the investigation of resting-state connectivity in the rodent, and is favored based on evidence that it presumably has a minimal effect on neural activity (Nasrallah et al, 2012): rs-fMRI correlations are more localized in contrast to other anesthetics, for example, isoflurane (Nasrallah et al, 2012) and it reveals functional connectivity maps in the rat that are more comparable to what is seen in humans (Williams et al, 2010). Studies of the interaction between anesthetics and pharmacological MRI responses to NMDA receptor antagonists (ketamine and phencyclidine) have suggested a dependence of the valence of the response on anesthesia (Hodkinson et al, 2012), although this is likely to be due to a combined (anesthetic+NMDA receptor antagonist) dose effect (Gozzi et al, 2008), where at higher combined doses the overall effect is one of sedation (depressed cortical activity) rather than the excitatory profile observed at lower doses of anesthesia and/or NMDA receptor antagonist challenge. The fact that we did not observe a change in valence at the highest ketamine dose used in this study argues that the maintenance level of medetomidine used here was sufficiently light to avoid this major interaction confound. Together with the observation that our results are similar to the effects produced by ketamine on metabolic activity in conscious rats as well as consistent with human data (Driesen et al, 2013), we consider that drug-anesthetic interaction was not a dominant factor in the results of this study. 
This study was the first to examine the effects of ketamine on resting state functional connectivity in the rat. As such, it was exploratory in nature; our main hypothesis before the study was that functional connectivity between the hippocampus and the prefrontal cortex would be altered, and we did find evidence supporting this. These findings yield more specific hypotheses to be tested in independent, confirmatory experiments: for example, that ketamine increases functional connectivity within the prefrontal cortex and between the subiculum area of the hippocampus and prefrontal regions, and that differential dose-response profiles are observed between these two sets of region pairs. To aid appropriate powering of such confirmatory studies, we report effect sizes for the atlas ROI pairs in the Supplementary Material (Supplementary Tables S1-S6).

In conclusion, ketamine-induced alterations in HC-PFC functional coupling corresponding to changes in behavior, EEG, and neurotransmission provide further evidence of rs-fMRI as a sensitive probe of central pharmacological effects in preclinical species. The finding of increased connectivity between the hippocampus and prefrontal cortex contrary to the data from schizophrenic patients suggests that ketamine effect does not necessarily parallel the disease pattern and might rather reflect a hyperglutamatergic state.

\section{FUNDING AND DISCLOSURE}

AJS is an employee and shareholder of Eli Lilly, CR is an employee of F Hoffmann-La Roche, MS and ES are employees of Instituts de Recherches Servier. AM-L received consultant fees and travel expenses from Alexza Pharmaceuticals, AstraZeneca, Bristol Myers Squibb, Defined Health, Decision Resources, Desitin Arzneimittel, Elsevier, F Hoffmann-La Roche, Gerson Lehrmann Group, Groupo Ferrer, Les Laboratoires Servier, Lilly Deutschland, Lundbeck Foundation, Outcome Sciences, Outcome Europe, Pricespective, Roche Pharma, speaker's fees from Abbott, AstraZeneca, BASF, Bristol-Myers Squibb, Glaxo SmithKline, Janssen Cilag, Lundbeck, Pfizer Pharma, and Servier Deutschland.

\section{ACKNOWLEDGEMENTS}

The authors thank Felix Hörner and Claudia Falfan-Melgoza for their excellent technical assistance. NEWMEDS-the research leading to these results, has received support from the Innovative Medicine Initiative Joint Undertaking under Grant Agreement No. 115008 of which resources are composed of European Federation of Pharmaceutical Industries and Associations (EFPIA) in-kind contribution and financial contribution from the European Union's Seventh Framework Programme (FP7/2007-2013). Also the work was supported by the BMBF (01EW1110) in the frame of ERA-Net NEURON.

\section{REFERENCES}

Autry AE, Adachi M, Nosyreva E, Na ES, Los MF, Cheng PF et al (2011). NMDA receptor blockade at rest triggers rapid behavioural antidepressant responses. Nature 475: 91-95.
Bandyopadhyaya D, Nizamie SH, Pradhan N, Bandyopadhyaya A (2011). Spontaneous gamma coherence as a possible trait marker of schizophrenia-An explorative study. Asian J Psychiatr 4: 172-177.

Chin CL, Upadhyay J, Marek GJ, Baker SJ, Zhang M, Mezler M et al (2011). Awake rat pharmacological magnetic resonance imaging as a translational pharmacodynamic biomarker: metabotropic glutamate 2/3 agonist modulation of ketamine-induced blood oxygenation level dependence signals. J Pharmacol Exp Ther 336: 709-715.

Cornwell BR, Salvadore G, Furey M, Marquardt CA, Brutsche NE, Grillon C et al (2012). Synaptic potentiation is critical for rapid antidepressant response to ketamine in treatment-resistant major depression. Biol Psychiatry 72: 555-561.

Crespo-Facorro B, Kim J, Andreasen NC, O'Leary DS, Bockholt HJ, Magnotta V (2000). Insular cortex abnormalities in schizophrenia: a structural magnetic resonance imaging study of firstepisode patients. Schizophr Res 46: 35-43.

Critchley HD, Wiens S, Rotshtein P, Ohman A, Dolan RJ (2004). Neural systems supporting interoceptive awareness. Nat Neurosci 7: 189-195.

Crossley NA, Mechelli A, Fusar-Poli P, Broome MR, Matthiasson P, Johns LC et al (2009). Superior temporal lobe dysfunction and frontotemporal dysconnectivity in subjects at risk of psychosis and in first-episode psychosis. Hum Brain Mapp 30: 4129-4137.

Doyle OM, De Simoni S, Schwarz AJ, Brittain C, O’Daly OG, Williams SC et al (2013). Quantifying the attenuation of the ketamine pharmacological magnetic resonance imaging response in humans: a validation using antipsychotic and glutamatergic agents. J Pharmacol Exp Ther 345: 151-160.

Driesen NR, McCarthy G, Bhagwagar Z, Bloch M, Calhoun V, D'Souza DC et al (2013). Relationship of resting brain hyperconnectivity and schizophrenia-like symptoms produced by the NMDA receptor antagonist ketamine in humans. Mol Psychiatry.

Duncan GE, Moy SS, Knapp DJ, Mueller RA, Breese GR (1998). Metabolic mapping of the rat brain after subanesthetic doses of ketamine: potential relevance to schizophrenia. Brain Res 787: 181-190.

Egerton A, Brugger S, Raffin M, Barker GJ, Lythgoe DJ, McGuire PK et al (2012). Anterior cingulate glutamate levels related to clinical status following treatment in first-episode schizophrenia. Neuropsychopharmacology 37: 2515-2521.

Fell MJ, Katner JS, Johnson BG, Khilevich A, Schkeryantz JM, Perry KW et al (2010). Activation of metabotropic glutamate (mGlu)2 receptors suppresses histamine release in limbic brain regions following acute ketamine challenge. Neuropharmacology 58: 632-639.

Gass N, Schwarz AJ, Sartorius A, Cleppien D, Zheng L, Schenker E et al (2012). Haloperidol modulates midbrain-prefrontal functional connectivity in the rat brain. Eur Neuropsychopharmacol 23: $1310-1319$.

Godsil BP, Kiss JP, Spedding M, Jay TM (2013). The hippocampalprefrontal pathway: The weak link in psychiatric disorders? Eur Neuropsychopharmacol 23: 1165-1181.

Goveas JS, Xie C, Ward BD, Wu Z, Li W, Franczak M et al (2011). Recovery of hippocampal network connectivity correlates with cognitive improvement in mild Alzheimer's disease patients treated with donepezil assessed by resting-state fMRI. J Magn Reson Imaging 34: 764-773.

Gozzi A, Schwarz A, Crestan V, Bifone A (2008). Drug-anaesthetic interaction in phMRI: the case of the psychotomimetic agent phencyclidine. Magn Reson Imaging 26: 999-1006.

Grunze HC, Rainnie DG, Hasselmo ME, Barkai E, Hearn EF, McCarley RW et al (1996). NMDA-dependent modulation of CA1 local circuit inhibition. J Neurosci 16: 2034-2043.

Grutzner C, Wibral M, Sun L, Rivolta D, Singer W, Maurer K et al (2013). Deficits in high- $(>60 \mathrm{~Hz})$ gamma-band oscillations 
during visual processing in schizophrenia. Front Hum Neurosci 7: 88 .

Hasler G, Northoff G (2011). Discovering imaging endophenotypes for major depression. Mol Psychiatry 16: 604-619.

Hodkinson DJ, de Groote C, McKie S, Deakin JF, Williams SR (2012). Differential effects of anaesthesia on the phMRI response to acute ketamine challenge. $\mathrm{Br} J \mathrm{Med}$ Med Res 2: 373-385.

Immordino-Yang MH, McColl A, Damasio H, Damasio A (2009). Neural correlates of admiration and compassion. Proc Natl Acad Sci USA 106: 8021-8026.

Isnard J, Magnin M, Jung J, Mauguiere F, Garcia-Larrea L (2011). Does the insula tell our brain that we are in pain? Pain 152: 946-951.

Javitt DC, Zukin SR, Heresco-Levy U, Umbricht D (2012). Has an angel shown the way? Etiological and therapeutic implications of the PCP/NMDA model of schizophrenia. Schizophr Bull 38: 958-966.

Jones TB, Bandettini PA, Birn RM (2008). Integration of motion correction and physiological noise regression in fMRI. Neuroimage 42: 582-590.

Kamiyama H, Matsumoto M, Otani S, Kimura SI, Shimamura KI, Ishikawa $S$ et al (2011). Mechanisms underlying ketamineinduced synaptic depression in rat hippocampus-medial prefrontal cortex pathway. Neuroscience 177: 159-169.

Kubota T, Anzawa N, Hirota K, Yoshida H, Kushikata T, Matsuki A (1999). Effects of ketamine and pentobarbital on noradrenaline release from the medial prefrontal cortex in rats. Can J Anaesth 46: $388-392$.

Large CH (2007). Do NMDA receptor antagonist models of schizophrenia predict the clinical efficacy of antipsychotic drugs? J Psychopharmacol 21: 283-301.

Levanen J, Makela ML, Scheinin H (1995). Dexmedetomidine premedication attenuates ketamine-induced cardiostimulatory effects and postanesthetic delirium. Anesthesiology 82: 1117-1125.

Littlewood CL, Jones N, O’Neill MJ, Mitchell SN, Tricklebank M, Williams SC (2006). Mapping the central effects of ketamine in the rat using pharmacological MRI. Psychopharmacology (Berl) 186: 64-81.

Lorrain DS, Baccei CS, Bristow LJ, Anderson JJ, Varney MA (2003). Effects of ketamine and N-methyl-D-aspartate on glutamate and dopamine release in the rat prefrontal cortex: modulation by a group II selective metabotropic glutamate receptor agonist LY379268. Neuroscience 117: 697-706.

Marsman A, van den Heuvel MP, Klomp DW, Kahn RS, Luijten PR, Hulshoff Pol HE (2013). Glutamate in schizophrenia: a focused review and meta-analysis of (1)H-MRS studies. Schizophr Bull 39: $120-129$.

Meyer-Lindenberg AS, Olsen RK, Kohn PD, Brown T, Egan MF, Weinberger DR et al (2005). Regionally specific disturbance of dorsolateral prefrontal-hippocampal functional connectivity in schizophrenia. Arch Gen Psychiatry 62: 379-386.

Mion G, Villevieille T (2013). Ketamine pharmacology: an update (pharmacodynamics and molecular aspects, recent findings). CNS Neurosci Ther 19: 370-380.

Moghaddam B, Adams B, Verma A, Daly D (1997). Activation of glutamatergic neurotransmission by ketamine: a novel step in the pathway from NMDA receptor blockade to dopaminergic and cognitive disruptions associated with the prefrontal cortex. J Neurosci 17: 2921-2927.

Moore JW, Cambridge VC, Morgan H, Giorlando F, Adapa R, Fletcher PC (2013). Time, action and psychosis: using subjective time to investigate the effects of ketamine on sense of agency. Neuropsychologia 51: 377-384.

Nasrallah FA, Tan J, Chuang KH (2012). Pharmacological modulation of functional connectivity: alpha2-adrenergic receptor agonist alters synchrony but not neural activation. Neuroimage 60: 436-446.

Niesters M, Khalili-Mahani N, Martini C, Aarts L, van Gerven J, van Buchem MA et al (2012). Effect of subanesthetic ketamine on intrinsic functional brain connectivity: a placebo-controlled functional magnetic resonance imaging study in healthy male volunteers. Anesthesiology 117: 868-877.

Phillips KG, Cotel MC, McCarthy AP, Edgar DM, Tricklebank M, O'Neill MJ et al (2012). Differential effects of NMDA antagonists on high frequency and gamma EEG oscillations in a neurodevelopmental model of schizophrenia. Neuropharmacology 62: 1359-1370.

Pinault D (2008). N-methyl d-aspartate receptor antagonists ketamine and MK-801 induce wake-related aberrant gamma oscillations in the rat neocortex. Biol Psychiatry 63: 730-735.

Rotarska-Jagiela A, van de Ven V, Oertel-Knochel V, Uhlhaas PJ, Vogeley K, Linden DE (2010). Resting-state functional network correlates of psychotic symptoms in schizophrenia. Schizophr Res 117: 21-30.

Sato K, Wu J, Kikuchi T, Wang Y, Watanabe I, Okumura F (1996). Differential effects of ketamine and pentobarbitone on acetylcholine release from the rat hippocampus and striatum. Br J Anaesth 77: 381-384.

Scheidegger M, Walter M, Lehmann M, Metzger C, Grimm S, Boeker $\mathrm{H}$ et al (2012). Ketamine decreases resting state functional network connectivity in healthy subjects: implications for antidepressant drug action. PLoS One 7: e44799.

Schwarz AJ, Danckaert A, Reese T, Gozzi A, Paxinos G, Watson C et al (2006). A stereotaxic MRI template set for the rat brain with tissue class distribution maps and co-registered anatomical atlas: application to pharmacological MRI. Neuroimage 32: 538-550.

Schwarz AJ, Gass N, Sartorius A, Zheng L, Spedding M, Schenker E et al (2013). The low-frequency blood oxygenation level-dependent functional connectivity signature of the hippocampal-prefrontal network in the rat brain. Neuroscience 228: 243-258.

Seamans J (2008). Losing inhibition with ketamine. Nat Chem Biol 4: 91-93.

Tagliazucchi E, von Wegner F, Morzelewski A, Brodbeck V, Laufs H (2012). Dynamic BOLD functional connectivity in humans and its electrophysiological correlates. Front Hum Neurosci 6: 339.

van Buuren M, Gladwin TE, Zandbelt BB, van den Heuvel M, Ramsey NF, Kahn RS et al (2009). Cardiorespiratory effects on default-mode network activity as measured with fMRI. Hum Brain Mapp 30: 3031-3042.

Williams KA, Magnuson M, Majeed W, LaConte SM, Peltier SJ, Hu $\mathrm{X}$ et al (2010). Comparison of alpha-chloralose, medetomidine and isoflurane anesthesia for functional connectivity mapping in the rat. Magn Reson Imaging 28: 995-1003.

Zarate CA Jr, Singh JB, Carlson PJ, Brutsche NE, Ameli R, Luckenbaugh DA et al (2006). A randomized trial of an $\mathrm{N}$-methyl-D-aspartate antagonist in treatment-resistant major depression. Arch Gen Psychiatry 63: 856-864.

Zhou Y, Shu N, Liu Y, Song M, Hao Y, Liu H et al (2008). Altered resting-state functional connectivity and anatomical connectivity of hippocampus in schizophrenia. Schizophr Res 100: 120-132.

Supplementary Information accompanies the paper on the Neuropsychopharmacology website (http://www.nature.com/npp) 